\title{
The Association of Estrogen Receptor Activity, Interferon Signaling, and MHC Class I Expression in Breast Cancer
}

In Hye Song

Seoul Saint Mary's Hospital https://orcid.org/0000-0001-6325-3548

Young-Ae Kim

TeogenTC Corp

Sun-Hee Heo

Asan Medical Center

Won Seon Bang

Asan Medical Center

Hye Seon Park

NeogenTC Corp

Yeon ho Choi

NeogenTC Corp

Heejae Lee

NeogenTC Corp

Jeong-Han Seo

NeogenTC Corp

Youngjin Cho

Asan Medical Center

Sung Wook Jung

Asan Medical Center

Hee Jeong Kim

Asan Medical Center

Sei Hyun Ahn

Asan Medical Center

Hee Jin Lee

Asan Medical Center

Gyungyub Gong ( $\square$ gygong@amc.seoul.kr)

Asan Medical Center 
Keywords: breast neoplasms, estrogens, receptors, estrogen, interferons, major histocompatibility complex, tumor-infiltrating lymphocytes

Posted Date: July 13th, 2021

DOI: https://doi.org/10.21203/rs.3.rs-511823/v2

License: (c) (1) This work is licensed under a Creative Commons Attribution 4.0 International License. Read Full License

Version of Record: A version of this preprint was published at Cancer Research and Treatment on December 21st, 2021. See the published version at https://doi.org/10.4143/crt.2021.1017. 


\section{Abstract}

Purpose: The expression of major histocompatibility complex class I (MHC I) has previously been reported to be negatively associated with estrogen receptor (ER) expression. Furthermore, the expression of MHC I, level of tumor-infiltrating lymphocytes (TILs), and expression of interferon (IFN) mediator MxA are positively associated with one another in human breast cancers. This study aimed to investigate the mechanisms of association of MHC I with estrogen and IFN signaling.

Methods: The human leukocyte antigen (HLA)-ABC protein expression was analyzed in breast cancer cell lines. The expressions of HLA-A and MXA mRNAs were analyzed in MCF-7 cells in Gene Expression Omnibus (GEO) data. ER and HLA-ABC expressions and TIL levels in tumor tissue were also analyzed in $\mathrm{ER}+/$ human epidermal growth factor receptor 2 (HER2)- breast cancer patients who randomly received either neoadjuvant chemotherapy or estrogen modulator treatment following surgical resection.

Results: HLA-ABC protein expression was decreased after $\beta$-estradiol treatment or hESR-GFP transfection and increased after fulvestrant or IFN-y treatment in breast cancer cell lines. In GEO data, HLA-A and MxA expression was increased after ESR1 shRNA transfection. When comparing the two patient groups, ER Allred score was significantly lower and the HLA-ABC expression and TIL levels were significantly higher in the estrogen modulator treated group than the chemotherapy treated group.

Conclusion: $\mathrm{MHC}$ I expression and TIL levels might be affected by ER pathway modulation and IFN treatment. Further studies elucidating the mechanism of $\mathrm{MHC}$ I regulation could suggest a way to boost TIL influx in cancer in a clinical setting.

\section{Introduction}

Tumor-infiltrating lymphocytes (TILs) have consistently been reported to play an important role in breast cancer.[1-7] TILs have a strong prognostic and predictive significance, particularly in triple-negative breast cancer (TNBC). CD8+ cytotoxic TILs are activated by the T cell receptor-recognition of a specific peptide, which is generally generated from endogenous proteins, and are presented by a major histocompatibility complex class I (MHC I) on the surface of tumor cells.[8] The recognition of these peptides by cytotoxic CD8+ TILs triggers a series of events that can result in tumor cell lysis. A better understanding of TILs and related features could facilitate the development of efficient immunotherapeutic approaches in breast cancer.

MHC I proteins are membrane proteins that are expressed on almost all nucleated cells and are encoded by human leukocyte antigen (HLA)-A, $-B$, and $-C$ genes.[9] The expression of HLAs varies from tissue to tissue and is largely stimulated by interferon (IFN) signaling.[10,11] The downregulation of HLAs is frequently observed in tumors and is reported to be correlated with disease progression.[10] Aberrant HLA expression in tumor cells might be caused by alterations in $H L A$ gene transcription, the translation of $H L A$ mRNA, or post-translational modifications. Torigoe et al.[12] established a monoclonal anti-pan HLA class I antibody suitable for the immunostaining of formalin-fixed tissue and found a high rate (85\%, 35 
out of 41 cases) of HLA downregulation in breast cancer compared with other malignancies $(20 \%-42 \%)$. Since HLA expression on tumor cells is important for the function of TILs, the downregulation of HLA might compromise the effective immune response in patients with breast cancer. Moreover, recent studies have reported increased IFN signaling in cancer cells and their association with a good response to anthracycline-based chemotherapy in breast cancer.[13] However, HLA expression, the level of IFN signaling activation, and their relationship in normal breast tissue and various subtypes of breast cancer have not been extensively studied.

We previously demonstrated the differential expression of HLA-ABC in breast cancer. HLA-ABC protein expression was negatively correlated with estrogen receptor (ER) protein expression but was not significantly correlated with human epidermal growth factor receptor 2 (HER2) protein expression.[14, 15] HLA-ABC expression was higher in TNBC and hormone receptor (HR)-/HER2+ breast cancers than in HR+ breast cancers, was positively correlated with TILs, and was associated with better clinical outcomes in breast cancer patients. $[1,14,15]$ In The Cancer Genome Atlas (TCGA) data analysis, HLA-A gene expression was positively correlated with $C D 8 B$ gene expression but was not significantly correlated with the total number of mutations. Instead, $H L A s, C D 3$, and $C D 8$ gene expression were positively correlated with IFN receptor genes and the IFN-inducible $M x A$ gene.[14] Additionally, MxA protein expression was higher in TNBC than in other types of breast cancer, was positively correlated with TIL levels, and was associated with better clinical outcomes.[16] Therefore, it can be hypothesized that ER activity, IFN signaling, and $\mathrm{MHC}$ I expression regulate one another and influence TIL influx.

The current study aimed to clarify the mechanisms of the association of MHC I with estrogen and IFN signaling.

\section{Materials And Methods}

\section{Cell lines, cultures, drug treatments, and plasmid transfections}

This study used breast cancer cell lines obtained from ATCC, including ERa+ (MCF-7 and T47D) and ERa(MDA-MB-231). The MCF-7 cells were maintained in Dulbecco's Modified Eagle Medium (Cat No. 11995, Life Technologies, Grand Island, NY) supplemented with 10\% fetal bovine serum (Cat No. 16000, Invitrogen, Carlsbad, CA) and 1\% penicillin/streptomycin (Cat No. 15140, Invitrogen). The T47D and MDAMB-231 cells were grown in Roswell Park Memorial Institute 1640 (Gibco, El Paso, TX) supplemented with $10 \%$ fetal bovine serum and $1 \%$ penicillin/streptomycin. All cells were cultured at $37^{\circ} \mathrm{C}$ in the presence of $5 \% \mathrm{CO}_{2}$. The cells were starved for 24 hours and treated with ICl (fulvestrant, Sigma-Aldrich, St. Louis, MO, 1 to $10 \mu \mathrm{M}$ ), IFN-y (R\&D Systems, Minneapolis, MN, 100 units/ml), or $\beta$-estradiol (Sigma-Aldrich, $1 \mathrm{nM}$ ) in $2 \mathrm{ml}$ of medium for an appropriate time. The cells were then used in the protein expression assays.

For the ESR1 plasmid transfection, ERa-cells were plated and cultured in a 6-well plate at $90 \%$ confluency and transfected with $2.5 \mu \mathrm{g}$ of hESR-GFP (Cat No. \#28230, Addgene, Cambridge, MA) using $3.75 \mu \mathrm{l}$ of 
Lipofectamine ${ }^{\circledR} 3000$ reagent (Life Technologies) and $5 \mu$ l of P3000 ${ }^{\text {TM }}$ reagent (Life Technologies) per well according to the manufacturer's protocol.

\section{Protein isolation and Western blotting}

The cells were lysed with RIPA buffer, and the Pierce BCA Protein Assay Reagent Kit (Cat No. 23225, Thermo Fisher, Waltham, MA) was used to measure the protein concentration. Approximately $10 \mu \mathrm{g}$ of protein was separated by $10 \%$ SDS-PAGE and transferred to a PVDF membrane (Millipore, Bedford, MA). Table 1 summarizes the antibodies used for protein detection. Equal loading of the protein samples was verified with an antibody to $\beta$-actin. Immunoreactive signals were detected with the Promega Western Blot Detection System (Cat No. W1008).

\section{GEO data analysis}

We analyzed one dataset from the GEO database that included Affymetrix RNA microarray analysis data from MCF-7 breast cancer cells that were transfected with ESR1 shRNA (5'-

GCTTCAGGCTACCATTATGttcaagagacataATGGTAGCCTGAAGCttttttacgcgt -3') (accession number: GDS4061).[17] The fold changes of ESR1, HLA-A, and MXA mRNA expressions were calculated.

\section{Patients and tissue specimens}

A total of 126 patients who were diagnosed with ER+/HER2- invasive ductal carcinoma were randomized to receive either estrogen modulator treatment or chemotherapy for 24 weeks as their neoadjuvant systemic therapy.[18] We analyzed the clinicopathologic data of the patients and the HLA-ABC and ER protein expressions and TIL levels in the pre-neoadjuvant biopsy tissues and the post-neoadjuvant resected tissues.

\section{Histological evaluation}

The histologic type was defined based on the 2012 WHO classification criteria, and the histologic grade was assessed using the modified Bloom-Richardson classification.[19] The hematoxylin and eosin (H\&E)-stained slides were histopathologically analyzed for TILs (defined as the percentage of the invasive carcinoma's stroma that was infiltrated by lymphocytes in $10 \%$ increments, if less than $10 \%$ of the stroma was infiltrated by TILs, $1 \%$ or $5 \%$ criteria were used, all available full sections were evaluated), histological subtype and grade, tumor size, pT stage, pN stage, and lymphovascular invasion.[1, 20] The tumor response to neoadjuvant systemic therapy was evaluated based on the Miller-Payne grade (1, no change, 2 , up to $30 \%$ reduction, $3,30-90 \%$ reduction, 4 , more than $90 \%$ reduction, 5 , no residual malignant cells). [21] A pathologic complete response ( $\mathrm{PCR}$ ) was defined as the absence of residual invasive cancer cells in the breast and lymph nodes.[22]

\section{Tissue microarray construction and immunohistochemical evaluation}


Among the 126 patients, fifty-six were available for formalin-fixed, paraffin-embedded (FFPE) tissue blocks of both biopsies and resected specimens. Each resected tissue sample was arrayed in three 1-mm diameter cores to minimize tissue loss and overcome tumor heterogeneity. Full sections of biopsy tissues and tissue microarray sections of the resected tissues were stained with an automatic immunohistochemical staining device (Benchmark XT, Ventana Medical Systems, Tucson, AZ). Table 2 summarizes the antibodies used for the immunohistochemical staining.

ER and progesterone receptor (PR) levels were regarded as positive if there was at least $1 \%$ positive tumor nuclei staining.[23] Additionally, the Allred score, which is the sum of the intensity score (0-3) and the proportion score (0-5), was calculated for the ER and PR.[24] HR+ tumors were defined as those determined to be ER-positive and/or PR-positive. HER2-overexpressing tumors were defined as those with scores of $3+$ according to the immunohistochemistry or gene amplification by silver in situ hybridization. [25] The HLA-ABC staining was semi-quantitatively evaluated as the $\mathrm{H}$-score, which is the product of the actual percentage of positive-stained cells and the intensity score (0-3), the $\mathrm{H}$-score can range from $\mathrm{0}-$ 300. We then categorized HLA-ABC expression in tumor cells as one of two levels (negative, $\mathrm{H}$-score $<50$, positive, $\mathrm{H}$-score $\geq 50$ ).

\section{Statistical analysis}

All statistical analyses were performed using $\mathrm{R}$ version 3.2.3.[26] The Wilcoxon rank-sum test, chi-square test, Fisher's exact test, and log-rank test were used as appropriate. All tests were two-sided, and statistical significance was set at $5 \%$.

\section{Results}

\section{The expression of HLA-ABC in breast cancer cell lines treated with ICI or IFN-Y}

We evaluated the expression of the HLA-ABC protein in the ER-positive cell lines (MCF-7 and T47D) and in an ER-negative cell line (MDA-MB-231) by Western blot analysis. The baseline HLA-ABC protein expression was higher in the MDA-MB-231 cell line than in the MCF-7 and T47D cell lines (Figure 1A). Next, we treated the MCF-7 cells with 1 to $10 \mu \mathrm{M}$ ICl, which is an ER downregulator, for 24 or 48 hours. The ER protein expression decreased and HLA-ABC increased with ICl treatment under all conditions (Figure 1B). When the MCF-7 cells were treated with 100 units/ml of IFN- $\gamma$ with or without $1 \mathrm{nM}$ of estradiol for 48 hours, the HLA-ABC protein expression was markedly increased (Figure 1C).

\section{The expression of HLA-ABC in the ER-negative breast cancer cell line transfected with hESR-GFP}

We also observed changes in the HLA-ABC protein expression in the ER-negative MDA-MB-231 breast cell line. Twenty-four or forty-the eight hours after transfection with the hESR-GFP plasmid, the MDA-MB-231 cells showed ER expression and decreased HLA-ABC protein levels (Figure 2A). When the MDA-MB-231 cells were treated with 100 units/ml of IFN- $y$ with or without $1 \mathrm{nM}$ of estradiol for 48 hours, HLA-ABC protein expression was markedly increased (Figure 2B). 


\section{The change of $H L A-A$ and $M X A$ mRNA expressions in breast cancer cell lines in the GEO data}

We also analyzed the HLA-A and MXA mRNA expressions in breast cancer cells from the GEO database. When the MCF-7 cells were transfected with ESR1 shRNA, the ESR1 mRNA expression decreased, and the $H L A-A$ and $M X A$ mRNA expressions increased (Figure 3). The fold changes were 0.360, 1.225 , and 1.156 for $E S R 1, H L A-A$, and $M x A$, respectively.

\section{The changes of ER and HLA-ABC expressions and TIL levels after neoadjuvant chemotherapy or estrogen modulators in breast cancer patients}

The clinicopathologic characteristics of the 126 patients who randomly received chemotherapy (Adriamycin and cyclophosphamide) or estrogen modulator treatment (tamoxifen and goserelin) as their neoadjuvant systemic therapy and following surgical resection were analyzed (Table 3 ). Before the neoadjuvant therapy, there were no differences between the two groups in patient age, $\mathrm{cT}$ and $\mathrm{cN}$ stages, ER Allred score, and TIL levels in biopsy specimens. After neoadjuvant therapy, no significant difference was observed in the $\mathrm{pCR}$ ratio $(P=0.058)$. However, the chemotherapy group showed significantly lower ypT and ypN stages ( $P<0.001$ and $P=0.016$, respectively) and a more reduced tumor burden according to the Miller-Payne grade $(P<0.001)$. The estrogen modulator group showed more frequent lymphovascular invasion $(P=0.046)$, a lower ER Allred score $(P=0.027)$, and higher TIL levels $(P<0.001)$ in resected specimens than the neoadjuvant chemotherapy group (Figures 4 and 5 ).

Next, we evaluated HLA-ABC expression in both the biopsy and resection tissues of fifty-six patients by immunohistochemistry (Table 3). Before neoadjuvant therapy, the HLA-ABC positivity in tumor cells did not differ significantly between the two groups $(P=0.243)$. After neoadjuvant systemic therapy, however, the estrogen modulator group showed higher HLA-ABC positivity than the chemotherapy group $(P=$ 0.038).

The overall survival and recurrence-free survival between the two groups did not differ significantly $(P=$ 0.396 and 0.758 , respectively) (Figure 6).

\section{Discussion}

Recently, the significance of TILs, particularly that of CD8+ cytotoxic T cells, in breast cancer has been revealed.[4, 27-29] The expression of MHC I proteins on the tumor cell surface is essential for CD8+ T cells to act, and several reports have documented the positive relationship between TIL levels and MHC I expression. We previously reported that TILs were more abundant in tumors with a stronger expression of HLA-ABC, and abundant TILs was an independent prognostic factor for better disease-free survival in HER2-positive breast cancer patients treated with chemotherapy and trastuzumab.[15] We also reported that the HLA-ABC expression of the tumor cells was positively correlated with TIL levels in consecutive breast cancer and TNBC cohorts.[14] Although some may think that high HLA-ABC expression is due to a high mutation rate and more immunogenic mutations, we previously revealed that the total number of mutations was not associated with HLA-A expression in the tumor,[14] and Spranger et al. also reported 
that the density of nonsynonymous somatic mutations is not significantly associated with $\mathrm{T}$ cell related gene expression.[30]

Instead, some evidence has indicated that MHC I expression is related to ER expression and IFN signaling. In our previous study, HLA-ABC expression was negatively associated with ER expression in a consecutive breast cancer cohort and normal breast tissue, and HLA mRNA expression was positively correlated with IFN-associated gene expression in a TCGA and Cancer Cell Line Encyclopedia data analysis.[14] We also reported that the high expression of IFN-mediator MXA in the tumor cells was positively associated with TIL levels, CD8+ cell number, and stronger HLA-ABC expression and was an independent prognostic factor for better disease-free survival in breast cancer.[16] Although one article has reported that ERa signaling modulates IFN-y inducible MHC II expression through class II transactivator in breast cancer cells, the mechanism of the relationship between HLA-ABC expression, ER activity, and IFN signaling in breast cancers has never been reported.[31]

In the current study, we revealed that the expressions of HLA-ABC protein and HLA-A mRNA in breast cancer cells are negatively affected by ER signaling in vitro. We insist that this is a novel and important finding in addition to previously known tumor-intrinsic oncogenic pathways that have been suggested to be associated with the reduction of immune reactions, such as the WNT/ $\beta$-catenin pathway, the mitogenactivated protein kinase pathway, the PI3K/AKT pathway, MYC upregulation, and CDK4/6 activation. [32] The baseline HLA-ABC protein expression was higher in ER-negative cells than in ER-positive cells, and HLA-ABC protein expression was increased after ICl treatment and decreased after ER overexpression. HLA-A mRNA expression was also increased after ESR1 shRNA transfection. We also revealed a positive association between HLA-ABC and IFN signaling and a negative association between ER and IFN signaling. Breast cancer cells showed increased HLA-ABC protein expression after IFN treatment and decreased $M x A$ mRNA expression after ESR1 shRNA transfection. This is the first study that analyzed the relationship between HLA-ABC expression, ER activity, and IFN signaling in breast cancer in vitro.

We also analyzed the breast cancer tissues of patients who received either neoadjuvant chemotherapy or estrogen modulator therapy. We revealed that the HLA-ABC expression in breast cancer cells increased and ER expression decreased after neoadjuvant estrogen modulator treatment compared with neoadjuvant chemotherapy. Estrogen modulator treatment is known to negatively regulate ER signaling in breast cancer.[33] By combining the results of the in vitro experiments, our data suggested that ER signaling was downregulated by neoadjuvant estrogen modulator treatment, and this caused the increase of HLA-ABC expression in tumor cells. We also analyzed the TIL levels in biopsies and resection tissues from the two groups. TIL levels were significantly decreased in resected tissue after neoadjuvant chemotherapy compared with biopsy tissue, which is concordant with a previous publication.[34] This might be explained by the fact that conventional chemotherapeutic agents are generally toxic to proliferative cells.[35] Although the HLA-ABC expression in tumor cells was increased in the estrogen modulator treatment group, we did not identify a significant change in TIL levels in the estrogen 
modulator treatment group. This is possibly due to the insufficient duration of neoadjuvant estrogen modulator therapy. Further studies with a longer duration of neoadjuvant treatment are necessary.

This study has several limitations. First, our data do not include in vitro results with estrogen treatment, the key molecule in ER signaling, or with tamoxifen treatment, an important selective ER modulator drug. Second, molecular mechanisms and mediators on how HLA-ABC expression and IFN signaling are regulated by ER signaling must be identified. Therefore, further experiments are necessary to more precisely define these molecular mechanisms. We suggest that more significant results might be obtained by future studies with more patient samples and a longer follow-up duration.

\section{Conclusions}

This study demonstrated that MHC I expression and TIL levels were affected by ER pathway modulation and IFN treatment. Further studies elucidating the mechanism of $\mathrm{MHC}$ I regulation could suggest a way to boost TIL influx in cancer in a clinical setting.

\section{Declarations}

\section{Funding}

This work was supported by the Asan Institute for Life Sciences, Asan Medical Center, Seoul, Korea (2019IP0732).

\section{Conflicts of interest}

The authors declare that they have no conflicts of interest.

\section{Availability of data and materials}

The datasets during and/or analysed during the current study available from the corresponding author on reasonable request.

\section{Code availability}

Not applicable

\section{Authors' contributions}

Conceptualization: HJL, GG

Design of the work: HJK, SHA, HJL, GG

Data acquisition: IHS, YK, SH, WSB, HSP

Data interpretation: IHS, HJL, GG 
Writing - original draft preparation: IHS

Writing - review and editing: All authors

Approval of final manuscript: All authors

\section{Ethics approval}

This study was approved by the Institutional Review Board of the Asan Medical Center.

\section{Consent for participate}

Not applicable

\section{Consent for publication}

Not applicable

\section{References}

1. Loi S, Sirtaine N, Piette F, Salgado R, Viale G, Van Eenoo F, Rouas G, Francis P, Crown JP, Hitre E, de Azambuja E, Quinaux E, Di Leo A, Michiels S, Piccart MJ, Sotiriou C (2013) Prognostic and predictive value of tumor-infiltrating lymphocytes in a phase III randomized adjuvant breast cancer trial in nodepositive breast cancer comparing the addition of docetaxel to doxorubicin with doxorubicin-based chemotherapy: BIG 02-98. J Clin Oncol 31:860-867. doi:10.1200/JC0.2011.41.0902

2. Denkert C, Loibl S, Noske A, Roller M, Muller BM, Komor M, Budczies J, Darb-Esfahani S, Kronenwett R, Hanusch C, von Torne C, Weichert W, Engels K, Solbach C, Schrader I, Dietel M, von Minckwitz G (2010) Tumor-associated lymphocytes as an independent predictor of response to neoadjuvant chemotherapy in breast cancer. J Clin Oncol 28:105-113. doi:10.1200/jco.2009.23.7370

3. Lee HJ, Seo JY, Ahn JH, Ahn SH, Gong G (2013) Tumor-associated lymphocytes predict response to neoadjuvant chemotherapy in breast cancer patients. J Breast Cancer 16:32-39. doi:10.4048/jbc.2013.16.1.32

4. Seo AN, Lee HJ, Kim EJ, Kim HJ, Jang MH, Lee HE, Kim YJ, Kim JH, Park SY (2013) Tumourinfiltrating CD8+ lymphocytes as an independent predictive factor for pathological complete response to primary systemic therapy in breast cancer. $\mathrm{Br} \mathrm{J}$ Cancer 109:2705-2713. doi:10.1038/bjc.2013.634

5. Mohammed ZM, Going JJ, Edwards J, Elsberger B, McMillan DC (2013) The relationship between lymphocyte subsets and clinico-pathological determinants of survival in patients with primary operable invasive ductal breast cancer. Br J Cancer 109:1676-1684. doi:10.1038/bjc.2013.493

6. Mohammed ZM, Going JJ, Edwards J, Elsberger B, Doughty JC, McMillan DC (2012) The relationship between components of tumour inflammatory cell infiltrate and clinicopathological factors and survival in patients with primary operable invasive ductal breast cancer. $\mathrm{Br} \mathrm{J}$ Cancer 107:864-873. doi:10.1038/bjc.2012.347 
7. Adams S, Gray RJ, Demaria S, Goldstein L, Perez EA, Shulman LN, Martino S, Wang M, Jones VE, Saphner TJ, Wolff AC, Wood WC, Davidson NE, Sledge GW, Sparano JA, Badve SS (2014) Prognostic value of tumor-infiltrating lymphocytes in triple-negative breast cancers from two phase III randomized adjuvant breast cancer trials: ECOG 2197 and ECOG 1199. J Clin Oncol 32:2959-2966. doi:10.1200/JCO.2013.55.0491

8. Phan GQ, Rosenberg SA (2013) Adoptive cell transfer for patients with metastatic melanoma: the potential and promise of cancer immunotherapy. Cancer Control 20:289-297

9. Brown SD, Warren RL, Gibb EA, Martin SD, Spinelli JJ, Nelson BH, Holt RA (2014) Neo-antigens predicted by tumor genome meta-analysis correlate with increased patient survival. Genome Res 24:743-750. doi:10.1101/gr.165985.113

10. Agrawal S, Kishore MC (2000) MHC class I gene expression and regulation. J Hematother Stem Cell Res 9:795-812. doi:10.1089/152581600750062237

11. Leone P, Shin EC, Perosa F, Vacca A, Dammacco F, Racanelli V (2013) MHC class I antigen processing and presenting machinery: organization, function, and defects in tumor cells. J Natl Cancer Inst 105:1172-1187. doi:10.1093/jnci/djt184

12. Torigoe T, Asanuma H, Nakazawa E, Tamura Y, Hirohashi Y, Yamamoto E, Kanaseki T, Hasegawa T, Sato N (2012) Establishment of a monoclonal anti-pan HLA class I antibody suitable for immunostaining of formalin-fixed tissue: unusually high frequency of down-regulation in breast cancer tissues. Pathol Int 62:303-308. doi:10.1111/j.1440-1827.2012.02789.x

13. Sistigu A, Yamazaki T, Vacchelli E, Chaba K, Enot DP, Adam J, Vitale I, Goubar A, Baracco EE, Remedios C, Fend L, Hannani D, Aymeric L, Ma Y, Niso-Santano M, Kepp O, Schultze JL, Tuting T, Belardelli F, Bracci L, La Sorsa V, Ziccheddu G, Sestili P, Urbani F, Delorenzi M, Lacroix-Triki M, Quidville V, Conforti R, Spano JP, Pusztai L, Poirier-Colame V, Delaloge S, Penault-Llorca F, Ladoire S, Arnould L, Cyrta J, Dessoliers MC, Eggermont A, Bianchi ME, Pittet M, Engblom C, Pfirschke C, Preville X, Uze G, Schreiber RD, Chow MT, Smyth MJ, Proietti E, Andre F, Kroemer G, Zitvogel L (2014) Cancer cell-autonomous contribution of type I interferon signaling to the efficacy of chemotherapy. Nat Med 20:1301-1309. doi:10.1038/nm.3708

14. Lee HJ, Song IH, Park IA, Heo SH, Kim YA, Ahn JH, Gong G (2016) Differential expression of major histocompatibility complex class I in subtypes of breast cancer is associated with estrogen receptor and interferon signaling. Oncotarget 7:30119-30132. doi:10.18632/oncotarget.8798

15. Lee HJ, Kim JY, Park IA, Song IH, Yu JH, Ahn JH, Gong G (2015) Prognostic Significance of TumorInfiltrating Lymphocytes and the Tertiary Lymphoid Structures in HER2-Positive Breast Cancer Treated With Adjuvant Trastuzumab. Am J Clin Pathol 144:278-288. doi:10.1309/AJCPIXUYDVZORZ3G

16. Kim YA, Lee HJ, Heo SH, Park HS, Park SY, Bang W, Song IH, Park IA, Gong G (2016) MxA expression is associated with tumor-infiltrating lymphocytes and is a prognostic factor in triple-negative breast cancer. Breast Cancer Res Treat 156:597-606. doi:10.1007/s10549-016-3786-z 
17. Al Saleh S, Al Mulla F, Luqmani YA (2011) Estrogen receptor silencing induces epithelial to mesenchymal transition in human breast cancer cells. PLoS One 6:e20610. doi:10.1371/journal.pone.0020610

18. Kim HJ, Noh WC, Lee ES, Jung YS, Kim LS, Han W, Nam SJ, Gong G, Kim HJ, Ahn SH (2020) Efficacy of neoadjuvant endocrine therapy compared with neoadjuvant chemotherapy in pre-menopausal patients with oestrogen receptor-positive and HER2-negative, lymph node-positive breast cancer. Breast Cancer Res 22:54. doi:10.1186/s13058-020-01288-5

19. Lakhani SR El, Schnitt SJ, Tan PH, van de Vijver MJ, editor (2012) WHO Classification of Tumours of the Breast., 4th edn. International Agency for Research on Cancer, Lyon

20. Salgado R, Denkert C, Demaria S, Sirtaine N, Klauschen F, Pruneri G, Wienert S, Van den Eynden G, Baehner FL, Penault-Llorca F, Perez EA, Thompson EA, Symmans WF, Richardson AL, Brock J, Criscitiello C, Bailey H, Ignatiadis M, Floris G, Sparano J, Kos Z, Nielsen T, Rimm DL, Allison KH, ReisFilho JS, Loibl S, Sotiriou C, Viale G, Badve S, Adams S, Willard-Gallo K, Loi S, International TWG (2015) The evaluation of tumor-infiltrating lymphocytes (TILs) in breast cancer: recommendations by an International TILs Working Group 2014. Ann Oncol 26:259-271. doi:10.1093/annonc/mdu450

21. Ogston KN, Miller ID, Payne S, Hutcheon AW, Sarkar TK, Smith I, Schofield A, Heys SD (2003) A new histological grading system to assess response of breast cancers to primary chemotherapy: prognostic significance and survival. Breast 12:320-327

22. Formenti SC, Spicer D, Skinner K, Cohen D, Groshen S, Bettini A, Naritoku W, Press M, Salonga D, Tsao-Wei D, Danenberg K, Danenberg P (2002) Low HER2/neu gene expression is associated with pathological response to concurrent paclitaxel and radiation therapy in locally advanced breast cancer. Int J Radiat Oncol Biol Phys 52:397-405

23. Hammond ME, Hayes DF, Wolff AC, Mangu PB, Temin S (2010) American society of clinical oncology/college of american pathologists guideline recommendations for immunohistochemical testing of estrogen and progesterone receptors in breast cancer. J Oncol Pract 6:195-197. doi:10.1200/JOP.777003

24. Harvey JM, Clark GM, Osborne CK, Allred DC (1999) Estrogen receptor status by immunohistochemistry is superior to the ligand-binding assay for predicting response to adjuvant endocrine therapy in breast cancer. $\mathrm{J}$ Clin Oncol 17:1474-1481

25. Wolff AC, Hammond ME, Hicks DG, Dowsett M, McShane LM, Allison KH, Allred DC, Bartlett JM, Bilous M, Fitzgibbons P, Hanna W, Jenkins RB, Mangu PB, Paik S, Perez EA, Press MF, Spears PA, Vance GH, Viale G, Hayes DF, American Society of Clinical O, College of American P (2014) Recommendations for human epidermal growth factor receptor 2 testing in breast cancer: American Society of Clinical Oncology/College of American Pathologists clinical practice guideline update. Arch Pathol Lab Med 138:241-256. doi:10.5858/arpa.2013-0953-SA

26. Team RC (2015) R: A Language and Environment for Statistical Computing. 3.2.3 edn

27. Mahmoud SM, Paish EC, Powe DG, Macmillan RD, Grainge MJ, Lee AH, Ellis IO, Green AR (2011) Tumor-infiltrating CD8+ lymphocytes predict clinical outcome in breast cancer. J Clin Oncol 29:1949- 
1955. doi:10.1200/jco.2010.30.5037

28. Liu S, Lachapelle J, Leung S, Gao D, Foulkes WD, Nielsen TO (2012) CD8+ lymphocyte infiltration is an independent favorable prognostic indicator in basal-like breast cancer. Breast Cancer Res 14:R48. doi:10.1186/bcr3148

29. Song IH, Heo SH, Bang WS, Park HS, Park IA, Kim YA, Park SY, Roh J, Gong G, Lee HJ (2016) Predictive Value of Tertiary Lymphoid Structures Assessed by High Endothelial Venule Counts in the Neoadjuvant Setting of Triple-Negative Breast Cancer. Cancer Res Treat. doi:10.4143/crt.2016.215

30. Spranger S, Luke JJ, Bao R, Zha Y, Hernandez KM, Li Y, Gajewski AP, Andrade J, Gajewski TF (2016) Density of immunogenic antigens does not explain the presence or absence of the T-cell-inflamed tumor microenvironment in melanoma. Proc Natl Acad Sci U S A. doi:10.1073/pnas.1609376113

31. Mostafa AA, Codner D, Hirasawa K, Komatsu Y, Young MN, Steimle V, Drover S (2014) Activation of ERalpha signaling differentially modulates IFN-gamma induced HLA-class II expression in breast cancer cells. PLoS One 9:e87377. doi:10.1371/journal.pone.0087377

32. Anandappa AJ, Wu CJ, Ott PA (2020) Directing Traffic: How to Effectively Drive T Cells into Tumors. Cancer Discov 10:185-197. doi:10.1158/2159-8290.Cd-19-0790

33. Mandlekar S, Kong AN (2001) Mechanisms of tamoxifen-induced apoptosis. Apoptosis 6:469-477

34. Castaneda CA, Mittendorf E, Casavilca S, Wu Y, Castillo M, Arboleda P, Nunez T, Guerra H, Barrionuevo C, Dolores-Cerna K, Belmar-Lopez C, Abugattas J, Calderon G, De La Cruz M, Cotrina M, Dunstan J, Gomez HL, Vidaurre T (2016) Tumor infiltrating lymphocytes in triple negative breast cancer receiving neoadjuvant chemotherapy. World J Clin Oncol 7:387-394. doi:10.5306/wjco.v7.i5.387

35. Tannock IF (1986) Experimental chemotherapy and concepts related to the cell cycle. Int J Radiat Biol Relat Stud Phys Chem Med 49:335-355

\section{Tables}

Table 1. Experimental conditions for Western blotting.

\begin{tabular}{|lll|}
\hline Primary antibody & Provider & Dilution \\
\hline$\beta$-actin & Abcam, Cambridge, UK & $1: 3000$ \\
\hline ERa & Novus Biologicals, Littleton, CO & $1: 200$ \\
\hline HLA-ABC & Abcam, Cambridge, UK & $1: 3000$ \\
\hline Abbreviations: ER, estrogen receptor, HLA, human leukocyte antigen. \\
\hline
\end{tabular}

Table 2. List of antibodies for immunohistochemistry. 


\begin{tabular}{|llc|}
\hline Primary antibody & Provider & Dilution \\
\hline ER & Leica Biosystems, Newcastle, UK & $1: 200$ \\
\hline PR & Leica Biosystems & $1: 200$ \\
\hline HER2 & Ventana Medical Systems, Tucson, AZ & $1: 8$ \\
\hline HLA-ABC & Abcam, Cambridge, UK & $1: 1600$ \\
\hline $\begin{array}{l}\text { Abbreviations: ER, estrogen receptor, PR, progesterone receptor, HER2, human epidermal growth factor } \\
\text { receptor 2, HLA, human leukocyte antigen. }\end{array}$ & \\
\hline
\end{tabular}

Table 3. Comparison of clinicopathologic variables according to neoadjuvant systemic therapy in breast cancer patients. 


\begin{tabular}{|c|c|c|c|}
\hline \multirow[t]{2}{*}{ Variables } & \multicolumn{2}{|c|}{ Neoadjuvant systemic therapy } & \multirow[t]{2}{*}{$p$ value } \\
\hline & $\begin{array}{l}\text { Chemotherapy } \\
(n=65)\end{array}$ & $\begin{array}{l}\text { Estrogen modulator } \\
(\mathrm{n}=61)\end{array}$ & \\
\hline \multicolumn{4}{|l|}{ Pre-neoadjuvant } \\
\hline Age at diagnosis (years), & & & 0.784 \\
\hline Median (IQR) & $43(38-46)$ & $42(38-46)$ & \\
\hline cT & & & 0.522 \\
\hline 1 & $12(18.6)$ & $7(11.5)$ & \\
\hline 2 & $42(64.6)$ & $42(68.9)$ & \\
\hline 3 & $10(15.4)$ & $12(19.7)$ & \\
\hline 4 & $1(1.5)$ & $0(0.00)$ & \\
\hline $\mathrm{cN}$ & & & 1 \\
\hline 0 & $1(1.5)$ & $0(0.00)$ & \\
\hline 1 & $54(83.1)$ & $52(85.2)$ & \\
\hline 2 & $4(6.2)$ & $4(6.6)$ & \\
\hline 3 & $6(9.2)$ & $5(8.2)$ & \\
\hline ER Allred score in biopsy, & & & 0.467 \\
\hline Median (IQR) & $8(8-8)$ & $8(8-8)$ & \\
\hline HLA expression in biopsy & & & 0.243 \\
\hline Negative & $17(65.4)$ & $24(80.0)$ & \\
\hline Positive & $9(34.6)$ & $6(20.0)$ & \\
\hline TIL level in biopsy, & & & 0.514 \\
\hline Median (IQR) & $10(0-12.5)$ & $10(0-20)$ & \\
\hline \multicolumn{4}{|l|}{ Post-neoadjuvant } \\
\hline Histologic grade & & & 0.358 \\
\hline 1 & $4(6.9)$ & $3(5.0)$ & \\
\hline 2 & $46(79.3)$ & $53(88.3)$ & \\
\hline 3 & $8(13.8)$ & $4(6.7)$ & \\
\hline урт & & & $<0.001$ \\
\hline 0 & $7(10.8)$ & $1(1.6)$ & \\
\hline
\end{tabular}




\begin{tabular}{|c|c|c|c|}
\hline 1 & $32(49.2)$ & $12(19.7)$ & \\
\hline 2 & $20(30.8)$ & $37(60.7)$ & \\
\hline 3 & $6(9.2)$ & $9(14.8)$ & \\
\hline 4 & $0(0.0)$ & $2(3.3)$ & \\
\hline ypN & & & 0.016 \\
\hline 0 & $8(12.3)$ & $2(3.3)$ & \\
\hline 1 & $39(60.0)$ & $27(44.3)$ & \\
\hline 2 & $15(23.1)$ & $23(37.7)$ & \\
\hline 3 & $3(4.6)$ & $9(14.8)$ & \\
\hline Miller-Payne grade & & & $<0.001$ \\
\hline 1 & $2(3.1)$ & $20(32.8)$ & \\
\hline 2 & $10(15.4)$ & $24(39.3)$ & \\
\hline 3 & $36(55.4)$ & $14(23.0)$ & \\
\hline 4 & $10(15.4)$ & $2(3.3)$ & \\
\hline 5 & $7(10.8)$ & $1(1.6)$ & \\
\hline Pathologic complete response & & & 0.058 \\
\hline No & $60(92.3)$ & $61(100.0)$ & \\
\hline Yes & $5(7.7)$ & $0(0.0)$ & \\
\hline LVI & & & 0.046 \\
\hline Absent & $36(55.4)$ & $22(36.1)$ & \\
\hline Present & $29(44.6)$ & $39(63.9)$ & \\
\hline HLA expression in resected tissue & & & 0.038 \\
\hline Negative & $17(68.0)$ & $10(35.7)$ & \\
\hline Positive & $8(32.0)$ & $18(64.3)$ & \\
\hline TIL in resected tissue, & & & $<0.001$ \\
\hline Median (IQR) & $0(0-10)$ & $10(10-20)$ & \\
\hline
\end{tabular}

Abbreviations: AC, adriamycin + cyclophosphamide, ER, estrogen receptor, IQR, interquartile range, LVI, lymphovascular invasion, TIL, tumor-infiltrating lymphocyte. 


\section{Figures}

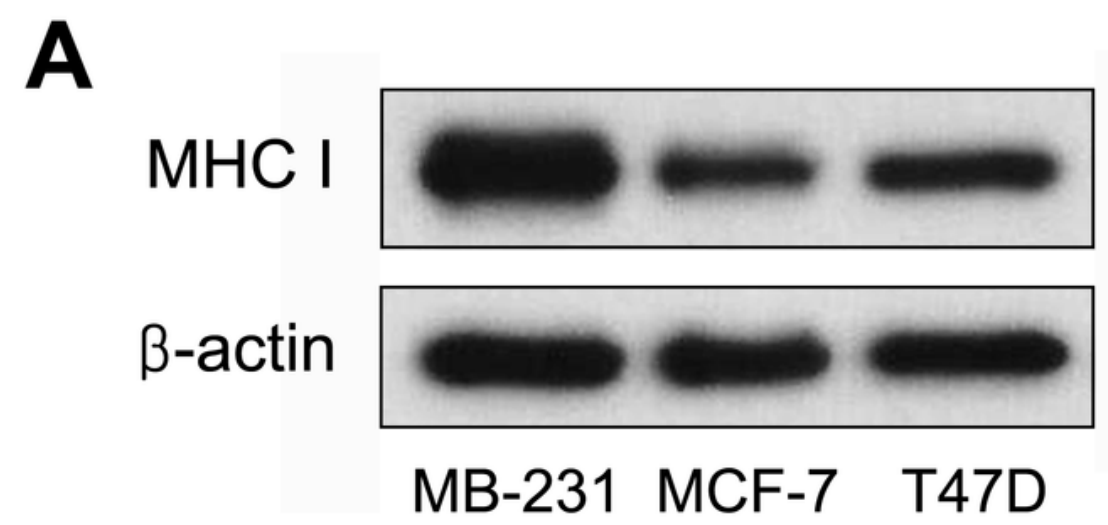

B
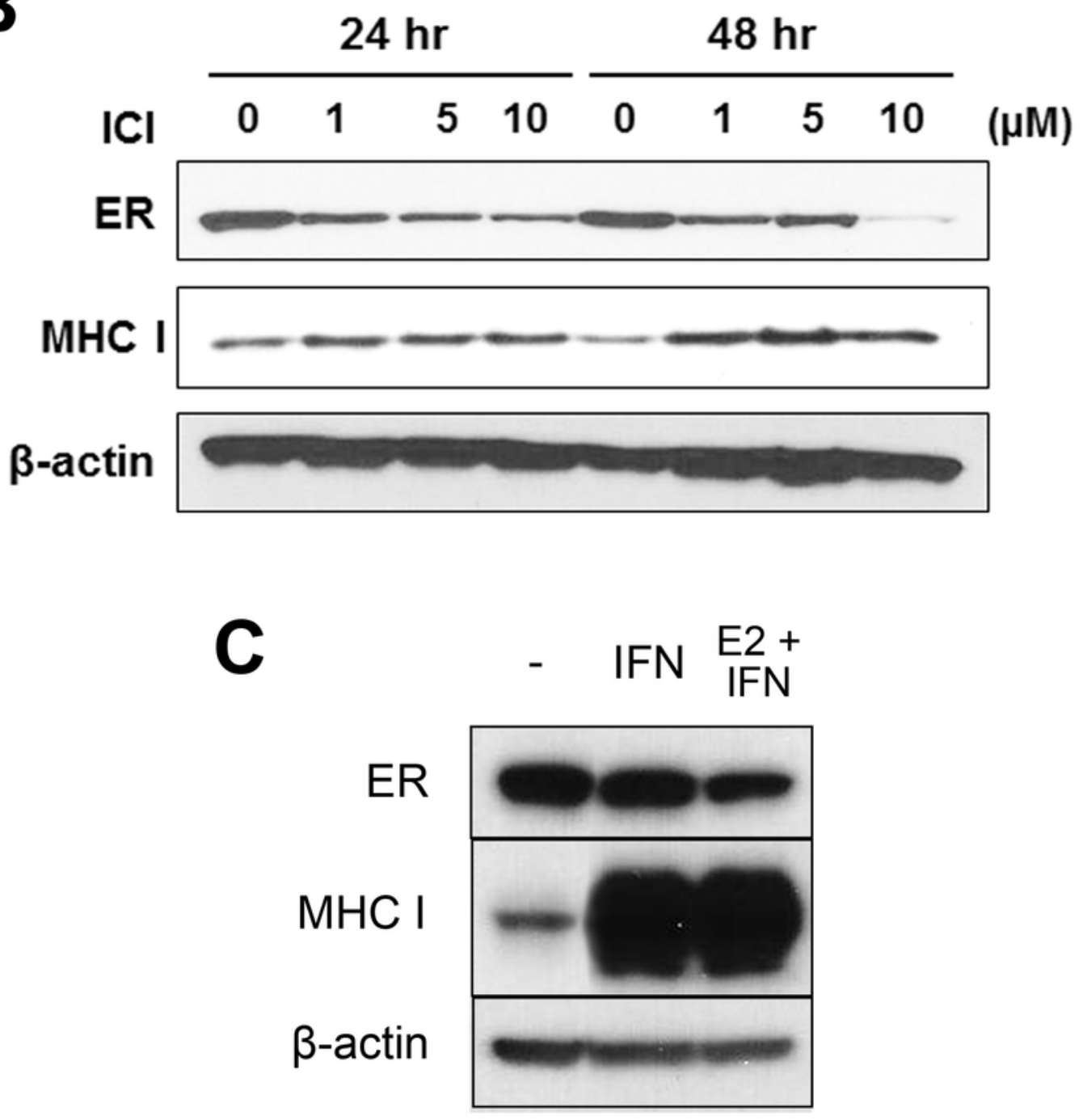

\section{Figure 1}

The effect of estrogen signaling and interferon signaling on HLA-ABC expression. (A) The baseline HLA$A B C$ protein expression is higher in ER-negative MDA-MB-231 cell lines than in ER-positive MCF-7 and T47D cell lines. (B) After 24 or 48 hours of ICI treatment (1 to $10 \mu \mathrm{M}$ ), the ER protein expression 
decreased, and HLA-ABC protein increased in MCF-7 cells. (C) The HLA-ABC protein expression increased in MCF-7 cells 48 hours after 100 units/ml of IFN-y treatment.
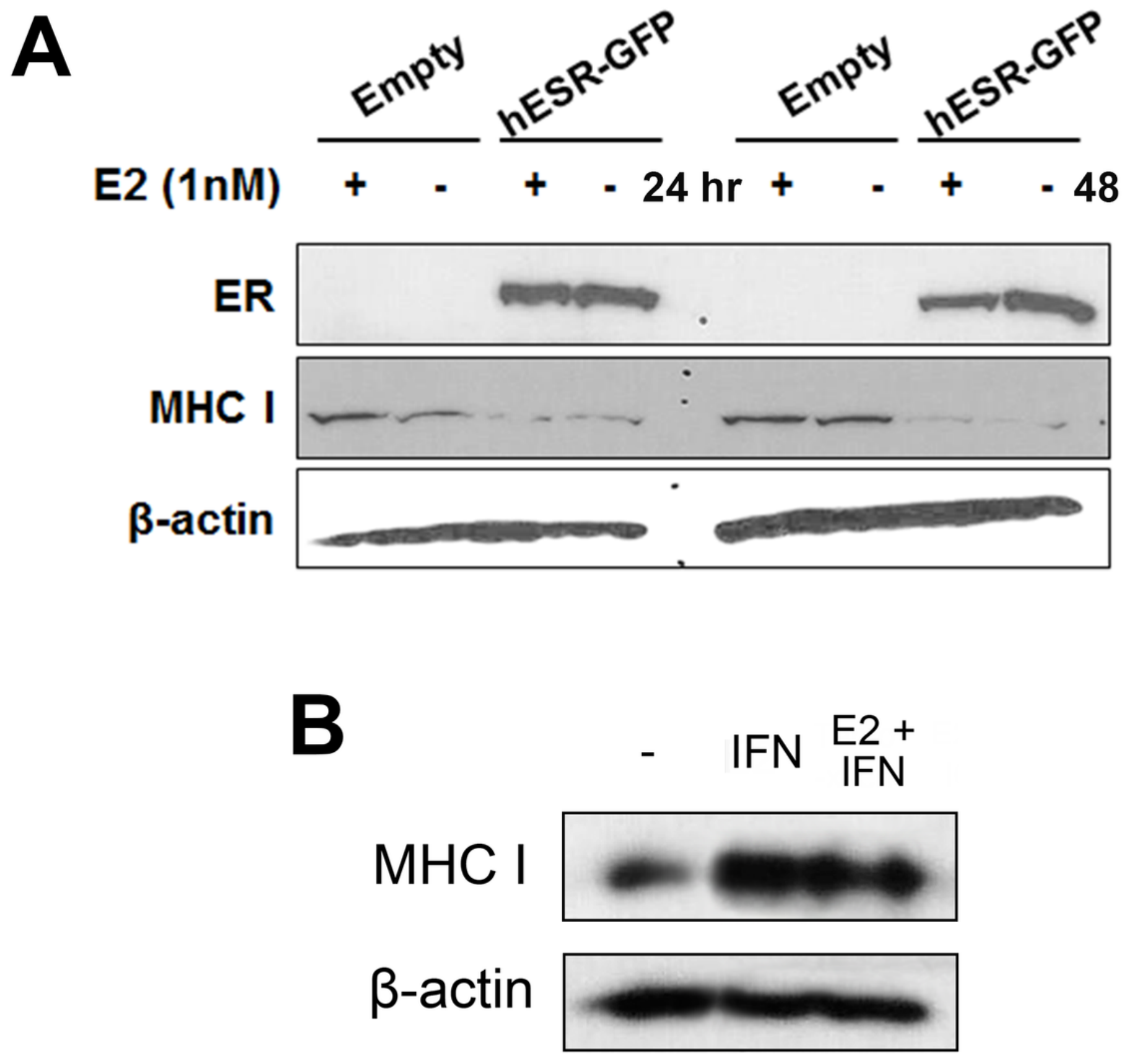

Figure 2

HLA-ABC protein expression in the MDA-MB-231 cells. (A) Twenty-four or forty-eight hours after transfection with the hESR-GFP plasmid, MDA-MB-231 cells show ER expression and decreased HLA-ABC protein levels. (B) The HLA-ABC protein expression was markedly increased 48 hours after $100 \mathrm{units} / \mathrm{ml}$ of IFN-y treatment in MDA-MB-231 cells. 
ESR1 expression

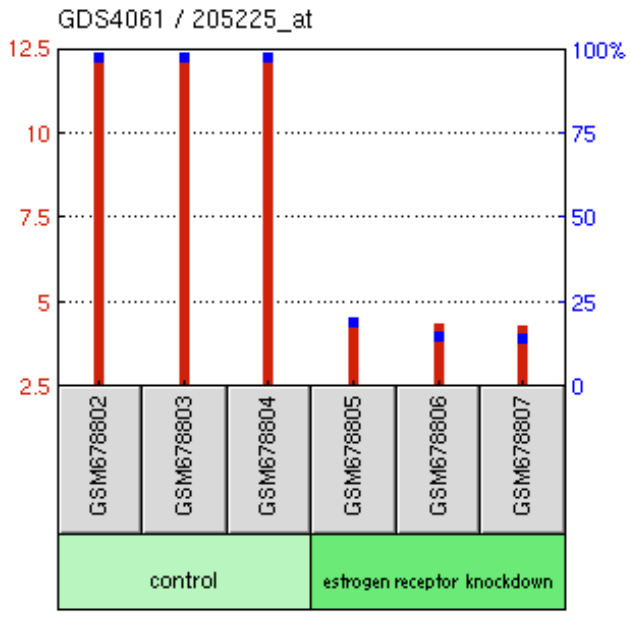

- transformed count

- percentile rank within the sample
HLA-A expression

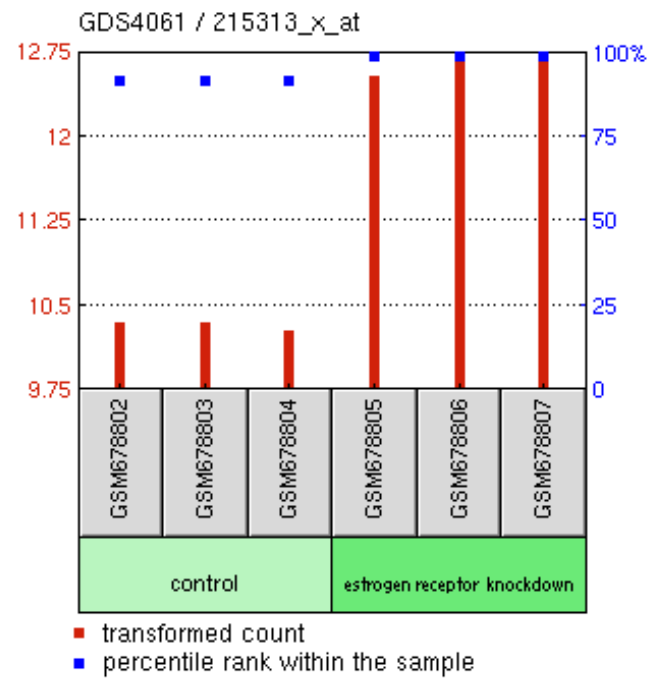

MxA expression

GDS4061/202086_at

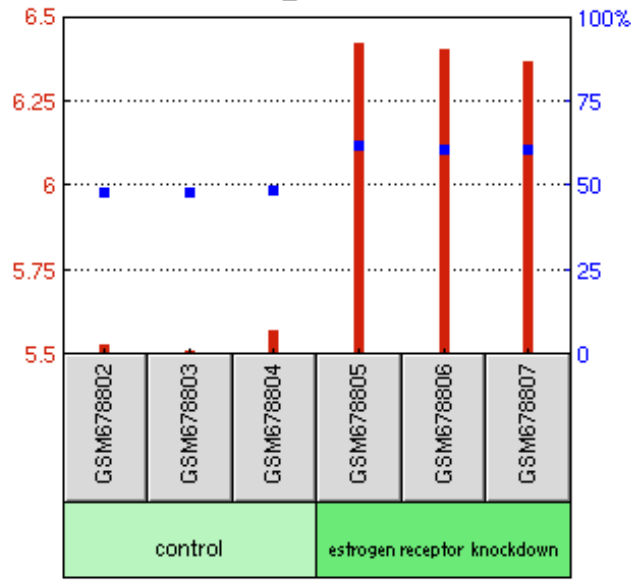

- transformed count

- percentile rank within the sample

Figure 3

The changes of mRNA expression in MCF-7 breast cancer cells after ESR1 shRNA transfection. ESR1 expression decreased after transfection (left), and HLA-A and MxA expressions increased after transfection (middle and right). 

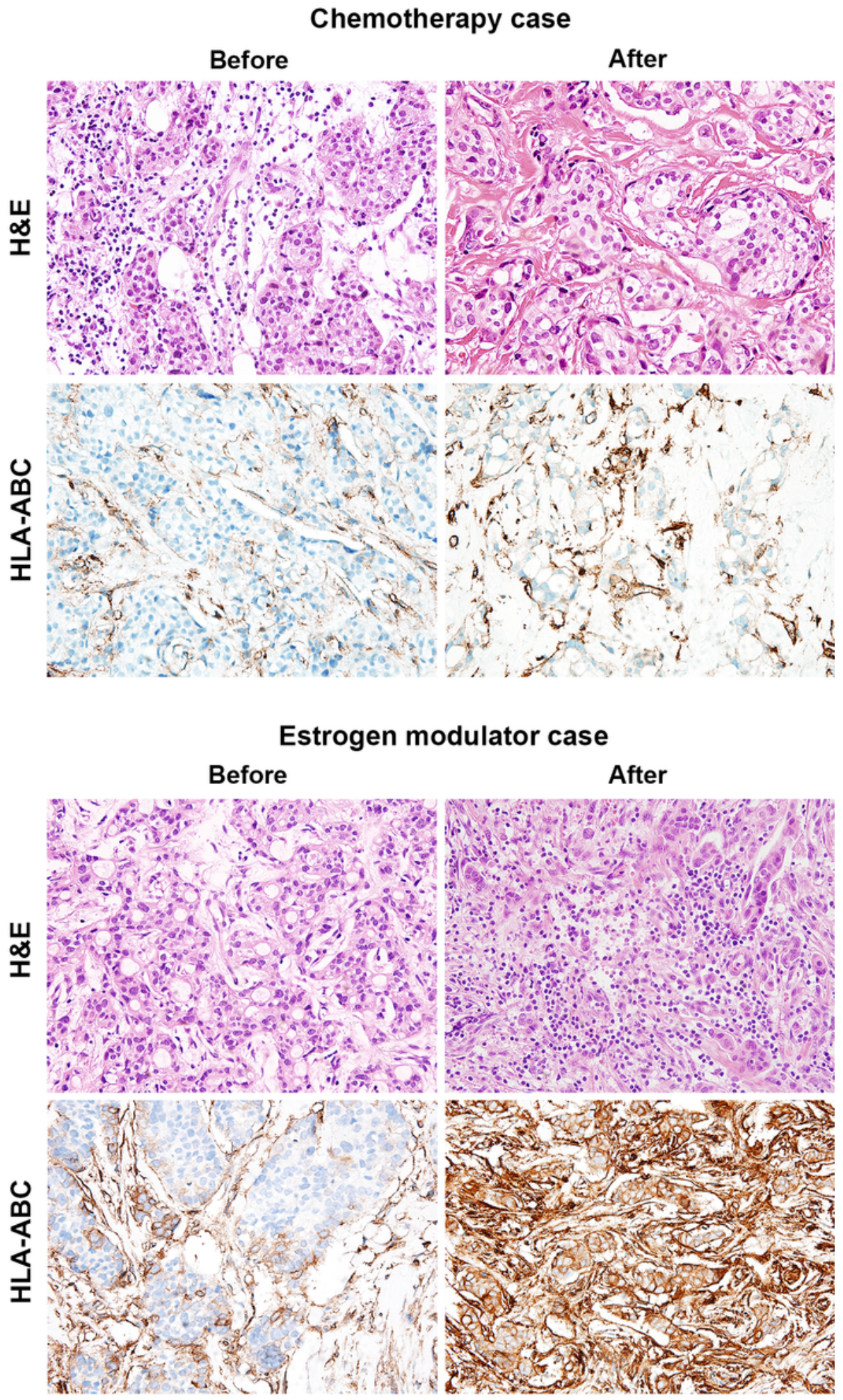

\section{Figure 4}

The microscopic images of breast tissue before and after chemotherapy or estrogen modulator treatment. In the patient who received neoadjuvant chemotherapy (the upper images), the quantity of tumor-infiltrating lymphocytes (TILs) decreased and HLA-ABC expression was similar in the resection specimen compared with the pre-neoadjuvant biopsy specimens. By contrast, the TIL levels and HLA-ABC 
expression increased after estrogen modulator treatment in the patient who received estrogen modulator treatment (Nolvadex and Zoladex, the lower images) $(\times 400)$.
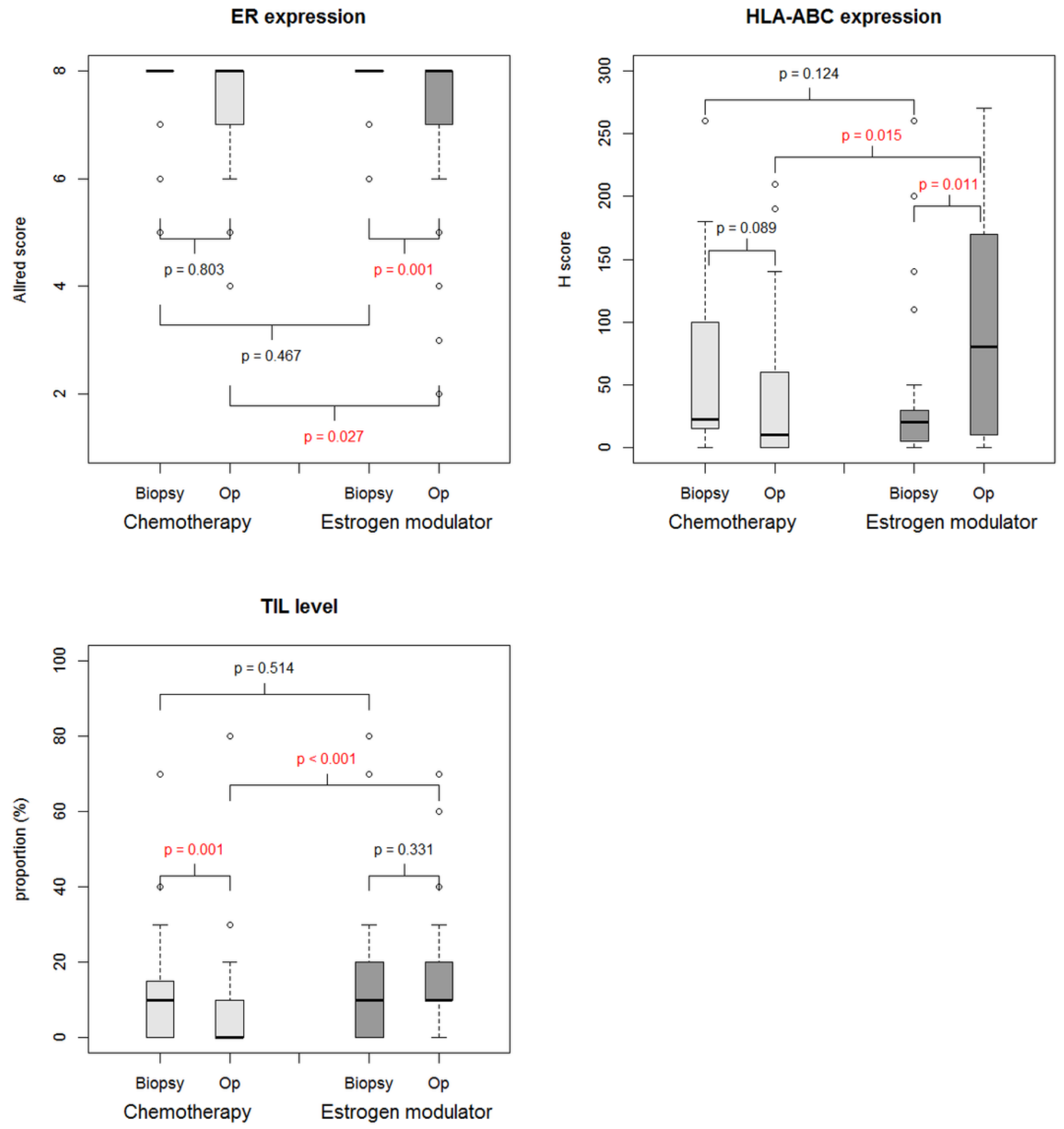

Figure 5

The changes of ER and human leukocyte antigen (HLA)-ABC expression and tumor-infiltrating lymphocyte (TIL) levels. The TIL levels significantly decreased after chemotherapy, while the expression 
of ER decreased after estrogen modulator treatment. Compared with the chemotherapy group, HLA-ABC expression increased significantly after estrogen modulator treatment (Op, operation).

A Overall survival

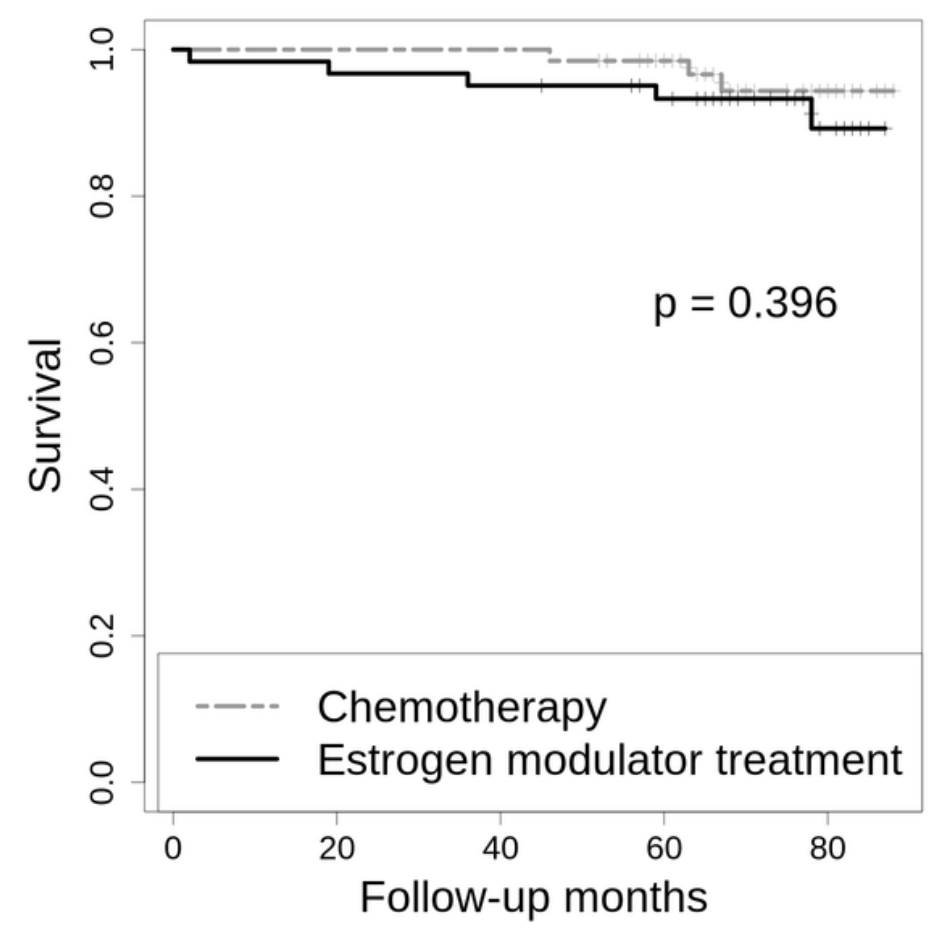

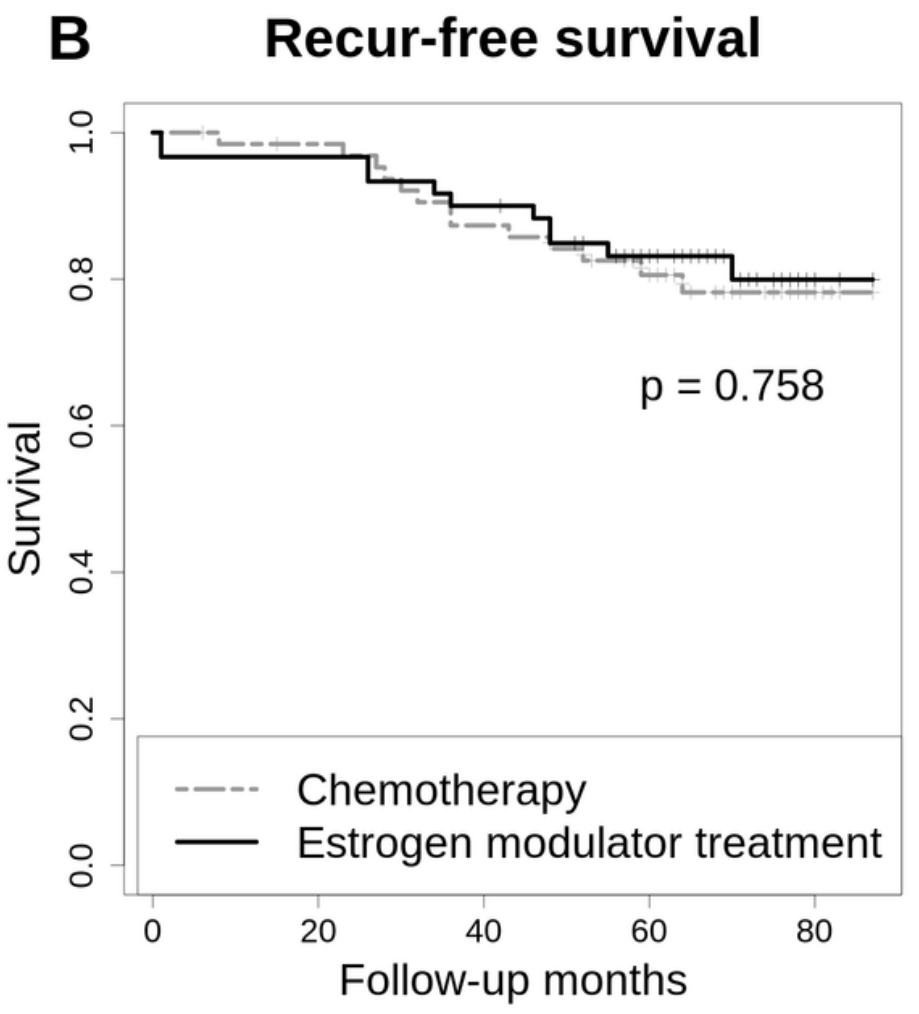

Figure 6

The overall and recurrence-free survival between the chemotherapy group and the estrogen modulator treatment group. 